\title{
Practical Training and Research on the Construction of Productive Practice Base in Higher Vocational Colleges -A Case Study of "Dayi Love Tea House" in Heyuan Poli Technic
}

\author{
Shi Wan $\mathrm{Li}^{1 *}$ \\ ${ }^{1}$ Hotel Management, Heyuan PolyTechnic, Heyuan, GuangDong517000, China \\ *Corresponding author. Email: 39088728@qq.com
}

\begin{abstract}
The construction of productive training base in higher vocational colleges is an important measure to deepen school-enterprise cooperation and cultivate high-quality technical talents. ${ }^{[1]}$ In order to solve the problems of teaching and production in the construction of productive training base in higher vocational colleges, Heyuan PolyTechnic has carried out beneficial exploration, through the joint investment of the college and enterprise to build "Dayi Love Tea House", and it has set up a team of double qualified teachers, carried out a series of practical teaching activities of teaching and production integration, formed a multi-guarantee mechanism, put forward a sustainable development model, and provided a plan for the construction of productive training base in higher vocational colleges.
\end{abstract}

Keywords: Training base, hotel management, practice, teaching, tea ceremony

\section{INTRODUCTION}

The on-campus productive practice base is a practical training base that higher vocational colleges make use of their own advantages, combine with the government, industry, enterprises or the society to fully develop the productive function of the base, achieve economic benefits through productive processes such as product production, social services, technology research and development, and realize the cultivation of students' practical skills in production. [2] As the only higher education institution in Heyuan City, Heyuan PoliTechnic, funded by Dayi love fund of Yunnan Province, has established Dayi love teahouse, the production and practice base of the college, and established the student organization "youth public welfare society". It effectively connects with the course "Basic Tea Art Service" in hotel management, takes tea as a medium, based on Heyuan, promote, spread and inherit the charity spirit of cherishing tea and loving people, and with value transfer as the concept, capacity building as the center, innovation and entrepreneurship as the focus, supports college students to independently carry out public welfare, cultural and income-generating activities through funding and income-generating activities, so as to cultivate students' comprehensive practical ability. In addition, according to the local economic characteristics of Heyuan City, it is committed to brand promotion of tea industry in Heyuan and tea culture spread, giving full play to the role and value of the productive training base on campus.

\section{THE PROCESS OF JOINTLY CONSTRUCTING THE PRODUCTIVE TRAINING BASE ON CAMPUS BY THE COLLEGE AND ENTERPRISES}

\subsection{Construction progress of "Dayi love teahouse"}

In 2015, the hotel management major of the college reached a cooperative intention with the Yunnan Dayi Love Foundation that Dayi Love Foundation donated money and our college contributed funds to jointly constructed productive training base Dayi Love Teahouse on campus. In order to make full use of the space and make the teahouse become a talent training base integrating teaching, training, vocational skills appraisal and technical services, education and research, a bridge for social enterprise training, a carrier for school-enterprise cooperation, and a platform for combining industry, before the construction of the tea house, relevant experts were organized to conduct field visits for many times, and the layout was carried out scientifically and reasonably. After the construction of the practice base, it could fully meet the needs of 50 people teaching practice at the same time. Relying on the Dayi Love Teahouse, the on-campus student group "Youth Public Benefit Society" was established to actively carry out practical activities such as tea culture communication, innovation and 
entrepreneurship, and mutual assistance, which provided an after-school practice stage for the hotel management students of our college.

\subsection{The college and enterprises jointly built an application-oriented teaching team for the practical teaching base}

The platform of college-enterprise cooperation was utilized to build a team of full-time and part-time teachers to improve the teaching quality, making up for the lack of practical experience of teachers and overcoming the difficulties in teaching that students were easily out of touch with industry requirements. Senior lecturers of Academy of Certified Chinese Tea Master were cooperated with to design course teaching methods and assessment standards, using the internal training materials of enterprises to improve the practical skills training in the course, so that students could be more closely connected with the actual development of the industry. The professional teacher team of Dayi Love Foundation were responsible for guiding the practice of student associations, carrying out tea culture promotion and social welfare activities, only consolidating the teaching content of the course, but also fully exercising the comprehensive quality and ability of students.

\subsection{The college and enterprises jointly constructed the course of "Basic Tea Art Service”}

In order to ensure the effective combination of teaching and productivity of the on-campus productive training base, after full research and analysis, combined with the course system of Academy of Certified Chinese Tea Master and the internal training content of Taetea Group, the teaching contents and teaching methods of the course "Basic Tea Art Service" in hotel management were scientifically set, Nine teaching modules, including tea history and culture, Chinese tea etiquette and six major tea categories, were selected to constitute the teaching content of the course. Teachers in the college were responsible for the main teaching tasks of the course, and some modules were decomposed and industry experts and enterprise mentors are invited to participate in the teaching. The course "Basic Tea Art Service" improved students' knowledge reserve of tea culture, exercised students' practical skills of tea art, and thus ensured the implementation of a series of productive activities in the productive training base on campus. ${ }^{[3]}$

\section{RELYING ON THE PRODUCTIVE TRAINING BASE ON CAMPUS TO CARRY OUT VARIOUS INNOVATIVE PRACTICES}

\subsection{Innovation and entrepreneurship activities ensure the sustainable development of the base}

Relying on the Dayi Love Teahouse, the team conducted a series of tea culture products and service projects according to the analysis of the market demand of the school teachers and students for the tea culture market, including leisure tea tasting, tea art performances, mid-autumn tea moon cake sales, and simulation of commodity sales activities on campus. The positioning of leisure tea tasting of Dayi Love Teahouse is service business to provide consumers with a tea room to enjoy tea products and services provided by the teahouse in the form of scattered spots, catering, cultural salons, etc. At the same time, Dayi Love Teahouse cooperated with students majoring in cooking to create the special tea cakes for Dayi Love Teahouse. Modern tea drinks and beverage were designed according to the consumption needs of modern young people, such as milk tea, ice cream, fruit tea and so on. The market competitiveness and attractiveness of the teahouse were maintained with diversified tea products.

\subsection{Tea culture communication activities contributed to the communication of Chinese outstanding traditional culture}

Chinese tea culture is an important part of Chinese traditional culture and an expression of outstanding traditional culture. In order to improve the spread of tea culture, relying on the teahouse platform, tea tastings, expert lectures, innovative tea performance contests, tea table design contests, tea mountain travels, chess clubs' joint competitions, reading parties and other activities were regularly carried out on campus, effectively spreading tea culture on campus. The propaganda and promotion of tea enterprises in Heyuan City were relatively poor, so the Youth Public Benefit Society actively participated in various promotional activities held by tea enterprises in Heyuan City to help increase the popularity of Heyuan tea industry. They supported Heyuan tea expo for three consecutive years, responsible for tea brewing, guidance and service during the exhibition, supported the first tea fair in Dongyuan County and the marketing activities of many tea enterprises in Heyuan, such as the spring harvest day of enterprises, the enterprise internal tasting, product network marketing design, staff tea art skills training and other activities. It enhanced the social image of our students while spreading the tea culture, and escorted the development of Heyuan tea industry. 


\subsection{Public welfare activities shaped the image of tea man who were willing to act and enjoy public welfare of contemporary college students}

Tea is a magical leaf that gives human beings many beautiful things. Contemporary college students should establish the image of "tea man" in the process of learning tea, cultivate the correct sense of value and worldview, promote the voluntary spirit of dedication, friendship, mutual assistance, and progress, and sincerely warm and help people in need. They should be positive and kindhearted and contribute all their enthusiasm to the Chinese Dream, which was also the heritage of Dayi Love Foundation's theory that "cherish tea and love people". With tea as a medium, the Youth Public Benefit Society used the income from the project for public welfare activities, carried out public benefit projects of cherishing tea and loving people on campus in virtue of tea promotion, tea culture communication and other ways, including freshmen serving tea, serving tea in teachers' day, Chinese parasol tea party lecture hall, charity sale and other activities, which had won unanimous praise from teachers and students.

Outside the school, they jointly created a colorful library for left-behind children and children of migrant workers with Heyuan Liangji Parents' Cultural Public Welfare Service Center. Through a series of activities such as companion reading, tutoring them in homework, setting up interest classes and loving families grow up together "hand in hand", the volunteers in the Youth Public Benefit Society guided left-behind children and children of migrant workers to complete homework, expand extracurricular knowledge, and enriched their after-school life, making children's lives as colorful as rainbow, to illuminate children's colorful lives with social love. While doing public welfare, the Youth Public Benefit Society has formed a unique public welfare brand, continuously helped all kinds of people in need, and constantly called for more people to participate in the public welfare.

\section{MECHANISM GUARANTEE OF THE PRODUCTIVE TRAINING BASE ON CAMPUS IOINTLY CONSTRUCTED BY COLLEGE AND ENTERPRISES}

\subsection{Campus mechanism guarantee}

The college attached great importance to the construction of the Dayi Love Teahouse, and the management of the training base was very sound. Every year, fixed funds were used for equipment purchase, consumables purchase, training room maintenance and other project expenditures, to support and encourage professional teachers to carry out teaching reforms and improve teaching abilities, which provided a strong guarantee for comprehensively improving the professional ability and comprehensive quality of teachers and students, and improving the school quality. The training base made sure that each fund was dedicated and the responsibilities were assigned to the designated person, completely in accordance with the financial system of the college to go through the application and approval process and the financial reimbursement process, making every payment transparent and scientific.

\subsection{Enterprise mechanism guarantee}

The hotel management major of our college and Yunnan Dayi Love Foundation had signed the "Donation Agreement on Teahouse Construction" and the scientific and technological service agreement on the "Youth Public Benefit Society Project" successively, to ensure the effective operation of the productive training base on campus. The college might apply to the foundation for activity funds ranging from 5,000 yuan to 20,000 yuan each year according to the completed progress of the public benefit society project. The foundation assigned special persons to guide the development of student activities and review the use of funds, while the college appointed designated teachers to manage the operation of the Youth Public Benefit Society. Each activity must have a detailed plan and summary, as well as clear expenditure details, which were uploaded to the foundation's designated APP.

\subsection{Student society mechanism guarantee}

The Youth Public Benefit Society of the college has a complete management mechanism, including selection, training, activity development, fund management and other aspects. Since the establishment of the Youth Public Benefit Society, after many discussions, summaries and revisions, finally a number of management systems were developed, such as "Articles of Public Service Team of the Youth Public Benefit Society", "Safety Management System of the Youth Public Benefit Society", "Financial Management Measures of the Youth Public Benefit Society" and "Volunteer Training and Growth Program of the Youth Public Benefit Society", which avoid the instability caused by the graduates' mobility and ensure the benign development of the Youth Public Benefit Society.

\section{REFLECTIONS ON THE PRODUCTIVE TRAINING BASE JOINTLY CONSTRUCTED BY THE COLLEGE AND ENTERPRISES}

After nearly 4 years of construction and development, our college's productive training base, "Dayi Love Teahouse", has achieved certain achievements in personnel training 
and quality development. Through sorting out the experience of constructing the productive training base jointly built by the university and enterprises, I think there are the following summary and sharing:

\subsection{The productive training base on campus should strive to create the "five-ization" practical training teaching model.}

The on-campus productive training base is a kind of practical training base that realizes the cultivation of students' practical skills in production. In order to ensure the implementation of productive practical training, ${ }^{[4]}$ it is necessary to have the support of curriculum teaching, the guidance of a professional team of teachers, and the implementation of practical activities in line with the actual needs of the college and the enterprise. To sum up, the productive training base of the college should be developed into a five-in-one productive training base integrating "practical teaching + skill training + product output + cultural communication + public welfare transmission", to create a "five-ization" practical teaching model of "actualization of training scene, projectization of practical training courses, professionalization of vocational training and teaching, enterprization of practical training management, and commercialization of practical training product". It should standardize the enterprise management of student associations, encourage students to produce more commodities suitable for the market, combine with the training goal of professional talents, and train students to be excellent talents in line with the needs of social development.

\subsection{Make full use of the campus productive training base to carry out innovation and entrepreneurship education and cultivate new innovative and entrepreneurial talents.}

The productive training base on campus should combine the national policies of deepening the reform of innovation and entrepreneurship education in colleges and universities and the "Internet +" college student innovation and entrepreneurship contest, make full use of the high-quality resources of enterprises, develop a college-enterprise collaborative education mechanism, rely on the on-campus productive training base, and integrate the innovation and entrepreneurship education into the cultivation of talent skills through the optimization of the curriculum system and teaching methods, so that the students can develop innovative and entrepreneurial capabilities while mastering specialized theories and strengthening professional skills training. ${ }^{[4]}$ The productive training base on campus and enterprise resources should be utilized to create a real production and operation environment for students, so as to make it a platform for the cultivation of innovation and entrepreneurship ability. Furthermore, it should encourage students to summarize the practical results in time, and guide students to participate in the "Internet+" college student innovation and entrepreneurship competition, so as to achieve the purpose of promoting learning through competition. $^{[5]}$

Use the on-campus productive training base and enterprise resources to create a real production and management environment for students, make it a platform for the cultivation of innovation and entrepreneurship, and encourage students to organize and summarize the practical results in time to guide students to participate in the "Internet $+"$ college students innovation and entrepreneurship competition, So as to achieve the purpose of promoting learning through competition.

\subsection{Improve the management system of training bases and develop students' sense of social responsibility and mission}

The effective operation of the productive practice base on campus will inevitably produce certain productive revenue. Reasonable utilization of capital can not only effectively stimulate students' enthusiasm for practice, but also help students establish correct sense of value and world view. The operation of the campus productive training base needs to be protected by strict management system, and the distribution and use methods of productive revenue should be clearly defined. Students are encouraged to invest their productive income in social practice of public welfare, so as to develop their sense of social responsibility and mission.

\section{CONCLUSION}

Campus productive training base is an important platform for training students' practical skills in higher vocational colleges. It needs the cooperation of industry, enterprise and school to establish a high-level professional teachers' guidance team inside and outside the school. Relying on the teaching content of relevant professional courses, a scientific and orderly student management team is established, and a complete management system is formed to ensure the effectiveness of various activities in the training base at the same time, it can train students' ability of innovation and entrepreneurship and social responsibility.

\section{ACKNOWLEDGMENT}

This paper is one of the phased achievements of the horizontal project (Youth benefit project No.: kys20190503) of Heyuan PoliTechnic in 2019. 


\section{REFERENCES}

[1] He Ying Lin, H. (2011) Discussion of the Productive Practice Bases in Higher Vocational Colleges. J. Journal of Shiyan Technical Institute., 02: $18-21$.

[2] Liu Song Hu, L.,Zhu Qing Song,Z.,Liang Guo Ben,L., Zhang Yan,Z., Wang Zhi Yong,W.(2011) Exploration and Reflection on the teaching reform of horticultural technology in Higher Vocational Colleges. J. Career Horizon., 01: 51-53.

[3] Zhu Zhi, Z.,Yang Hong Xia,Y.Yang Liang, Y.(2016) The exploration and practice of the university enterprise cooperation to build the practice teaching base outside the University. J. Journal of Huanggang Polytechnic., 18(05): 46-49.

[4] Li Li, L.,Huang He,H.(2019) On the training of innovative and entrepreneurial talents based on the productive training base in the University. J. Finance Theory and Teaching., 12: 111-113+118.

[5] Chen Chen, C. (2016) A survey of the influencing factors of business model innovation in the era of Internet" + ". J. Modern Business., 25: 127129. 